\title{
Product engineering design enhancing by parameterizing the 3D solid model
}

\author{
Marius Marian Cucos", Ionut Madalin Pista and Marius Ionut Ripanu \\ "Gheorghe Asachi” Technical University of Iasi, Department of Machine Manufacturing Technology, \\ Prof. D. Mangeron Street, no. 39A, Iasi, Romania
}

\begin{abstract}
The research approach and the case study presented in the paper are oriented towards the convergent use of a parametric modelling algorithm and of an advanced integrated $\mathrm{CAD} / \mathrm{CAE}$ solution for the optimization of the product engineering design, for reducing the product life cycle environmental impact and for providing sustainability in product development. First of all, a conceptual model for the research framework is proposed, where the use of mathematical models (equations/mathematical relations, etc.) integrated into advanced $\mathrm{CAD} / \mathrm{CAE}$ design solutions leads to parameterizing of the product structure and obtaining of some product component families (gears, shafts, screws, nuts, bushings, etc.). The presented case study refers to the application of the above outlined solutions for enhancing the design effectiveness and efficiency of $3 \mathrm{D}$ product assembly and part models (hereby exemplified for component parts like shafts and gears) for a particular construction of a technological device, using the powerful tools of the integrated product family Creo Parametric (Pro/Engineer) as mechanical design software. Some suitable conclusions are finally presented and some directions of further researches are also included.
\end{abstract}

\section{Introduction. Research problem statement}

Lately, customers have become very rigorous about product quality and that is why the manufacturers have begun to develop families of parameterized product models using parametric mechanical design software tools (Creo Parametric, NX, Inventor, etc.), to fully satisfy the customers' needs, while respecting the quality and the market delivery terms.

Parameterized design involves the assignment of some mathematical relationships/equations necessary to satisfy the final product development requirements, to the 3D models from the mechanical design process [1].

Parameterized design actually represents the generation of the 3D model geometry from the definition of a family of initial parameters or input parameters (mathematical relations, equations, algorithm, etc.) until defining the design of formal relationships between parameters and design elements [2].

Exploiting of advanced capabilities of parametric design of the CAD/CAE solutions represents a process based on algorithmic/mathematical thinking that enables the

\footnotetext{
*Corresponding author: cucos.marius91@yahoo.com
} 
expression of parameters as rules that together define, clarify and codify the relationships between the design intent and the response from design [3].

The case study and the theoretical considerations presented in the paper are part of a wider research approach regarding the optimization of product engineering design by improving the activities efficiency and effectiveness, by embedment of some principles, concepts, strategies, methods like: Parametric modeling for advanced mechanical design, Holistic Design, DfX (Design for eXellence), AD (Axiomatic Design) etc. [4, 5, 6].

\section{Conceptual model of the research approach}

A conceptual model for the theoretical research approach has been firstly elaborated and is proposed in Figure 1, where the parametric design principles converge with the use of powerful tools of an advanced engineering CAD/CAE solution toward enhancing the effectiveness and efficiency of the product engineering design.

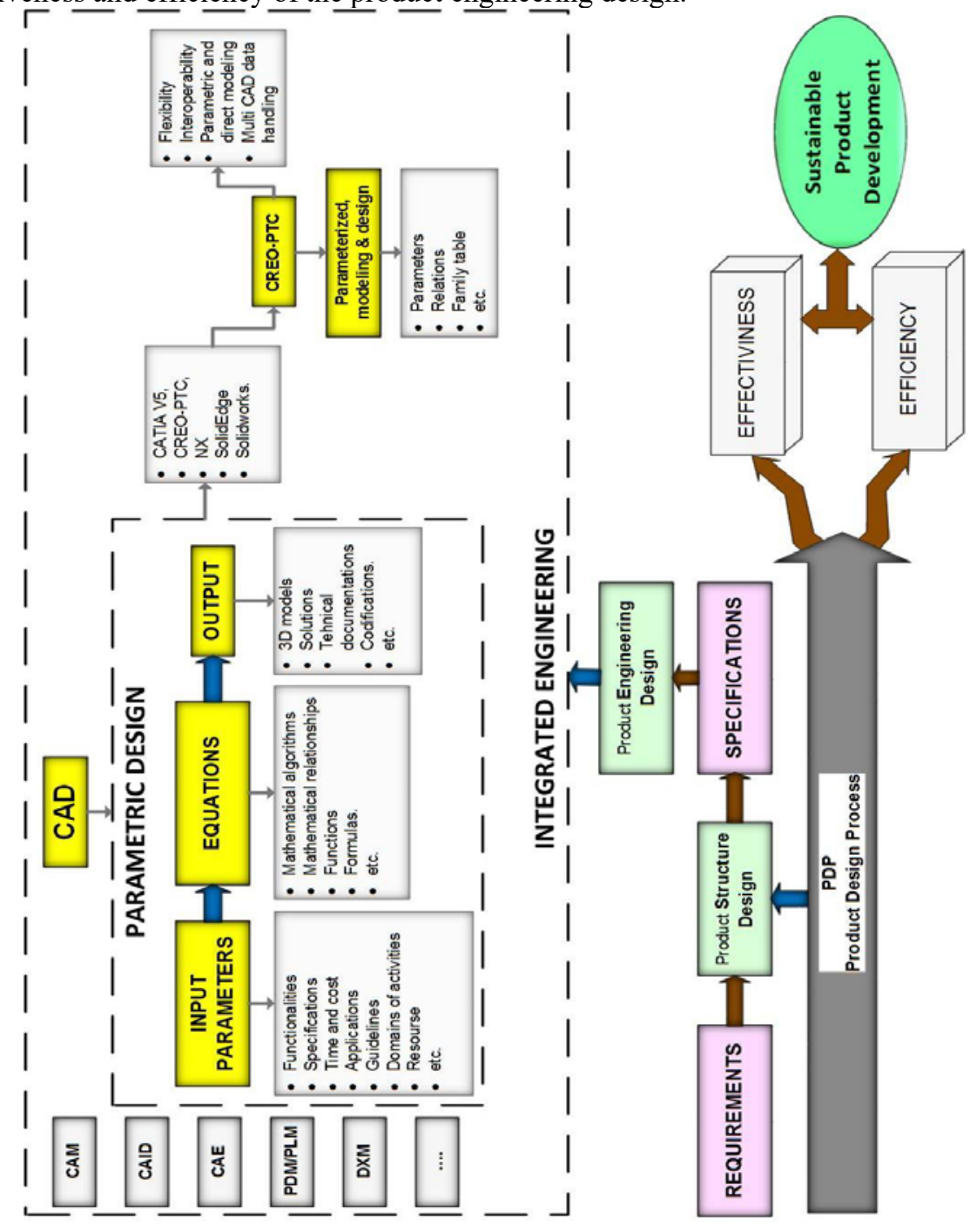

Fig. 1. Conceptual model for the research approach. 
The conceptual model of the above described research approach comes to support the current dynamics of needs and the sustainable development of the product structure and detailed engineering design. Starting from the product requirements defined as in the conceptual model from Figure 1, the processes of Product Structure Design and that of Product Engineering Design are oriented towards obtaining a sustainable set of Product Specifications and therefore Integrated Engineering tools are to be used [7], among them CAD (Computer-aided Design), CAM (Computer-aided Manufacturing), CAE (Computeraided Engineering), CAID (Computer-aided Industrial Design), PLM (Product Lifecycle Management), DXM (Data Exchange Management) etc. being nominated in the model. Based on the existing structure considered in the conceptual model for the parameterized design, the following requirements for the traceability of the product engineering design are considered: Input Parameters (functionalities, specifications, resources, etc.), Equations (mathematical algorithms, relationships, functions, formulas, etc.) and Output (3D models, solutions, technical documentation, codifications, etc.). The exploiting of the structure INPUT-EQUATIONS-OUTPUT provided by advanced engineering solutions leads to sustainable product development, to take advantage in a better way of the flexibility offered by CAD/CAE software, to obtain lower production cost by making better products and to reducing time to launch the product on the market.

\section{Case study. Approach results and discussions}

As case study, the research paper presents an approach on the application of the parameterized design principles (algorithms, formulas, mathematical relationships, etc) integrated into 3D Creo Parametric design software for increasing the effectiveness and efficiency of design activities in the development of product assembly and part models (hereby exemplified for component parts like shafts and gears) for a particular construction of a technological device.

\subsection{Product description}

The studied product shown in the below Figure 2 is a technological device able to generate cycloid profiles based on a double-planetary driving mechanism and being adaptable on an electrical discharge machine [8]. It has been previously redesigned using Creo PTC, [9].

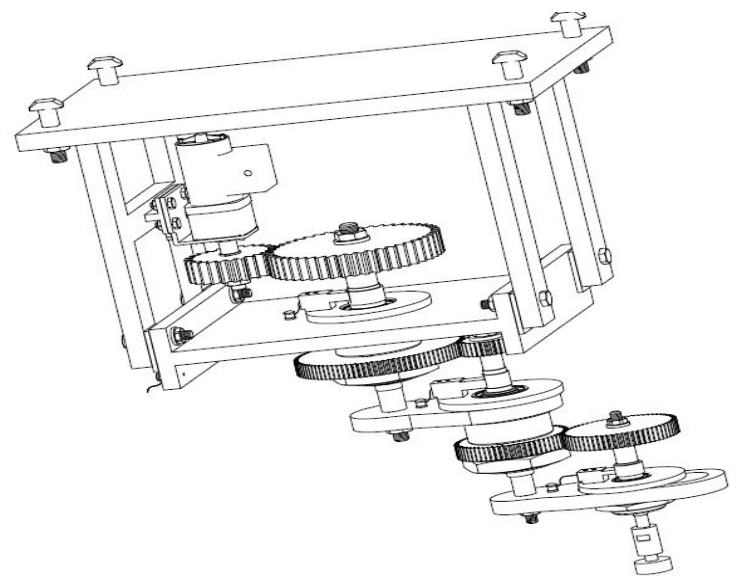

Fig. 2. Creo Parametric 3D model of the studied technological device - wireframe view [9]. 


\subsection{Optimized product engineering design using mathematical relationships integrated into Creo Parametric design software}

The exploiting of mathematical relationships into Creo Parametric [10] CAD/CAE design software is necessary to create a modular structure (family tables) and to optimize de design for the components of the technological device presented above.

Further on, is presented the traceability of the INPUT-EQUATIONS-OUTPUT parameterized design structure for reducing design time for shaft 1 and gear Z1 (Figure 3).

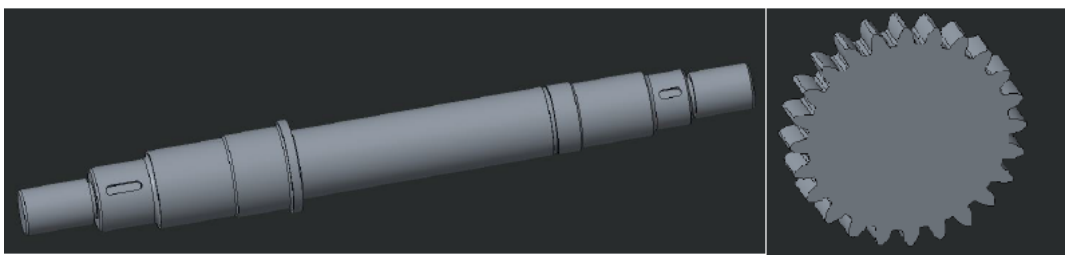

Fig. 3. 3D Models generated within Creo Parametric - Shaft 1 and Gear Z1=24.

\subsubsection{Input parameters}

First of all, for shaft 1 and gear Z1, above presented, there are defined the input parameters that are set before designing, and then integrated into the Creo Parametric design software. In Figure 4, presented below, some input parameters for gear: Z1 (number of teeth- 94), P (angle of engagement- $20^{\circ}$ ), M (module- $2 \mathrm{~mm}$ ), and for shaft: DIAMSECT1 (diameter for section1 - $\varnothing 8 \mathrm{~mm}$ ), RADIUS1 (radius for section $1-1 \mathrm{~mm}$ ), LGSECTION2 (length for section 2-13 mm), etc are shown.

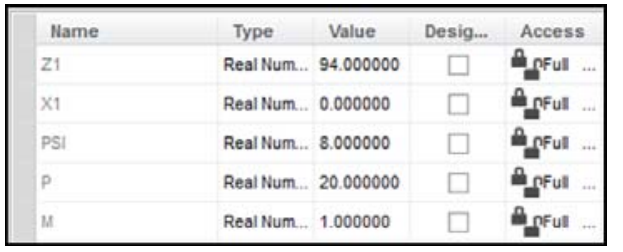

\begin{tabular}{|c|c|c|c|c|}
\hline Name & Type & Value & Desig... & Access \\
\hline DLAMSECT1 & Real Num... & 8.000000 & $\square$ & All .... \\
\hline RADIUS1 & Real Num.. & 1.000000 & $\square$ & $\ldots$ \\
\hline LGSECTION1 & Real Num.. & 16.000000 & $\square$ & \\
\hline LGSECTION2 & Real Num.. & 13.000000 & $\square$ & \\
\hline DLAMSECT3 & Real Num.. & 35.000000 & $\square$ & \\
\hline
\end{tabular}

Fig. 4. Input parameters for Shaft 1 and Gear Z1.

After setting the input parameters, PTC Creo Parametric provides the ability to associate the input parameters with some entities (sections, holes, chamfers, fillets, etc.), as it can be seen in Figure 5 where some encodings assigned by the software appear instead of normal view, and we need to use the "Switch Dimension" command to access these encodings.
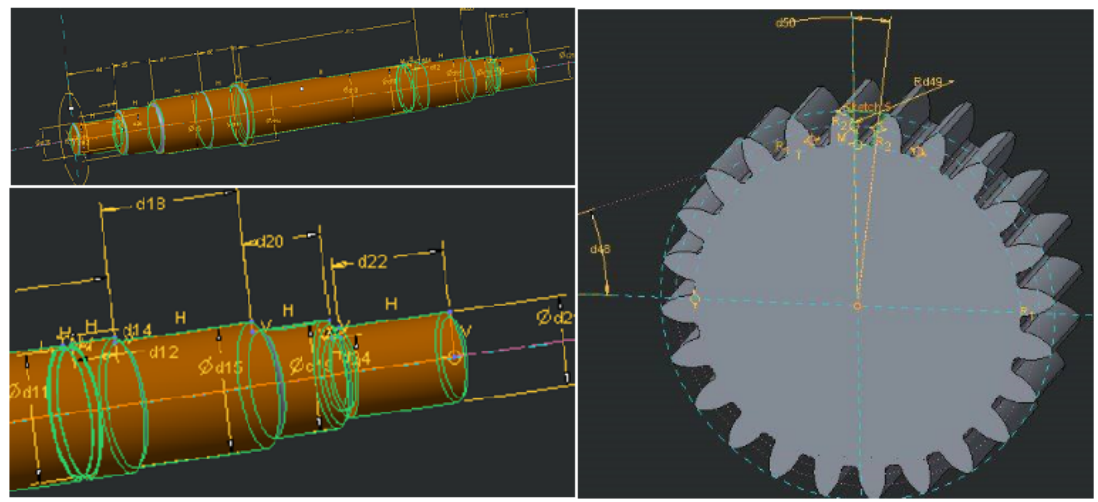

Fig. 5. Encodings for Shaft 1 and gear $Z 1$ assigned by Creo Parametric. 


\subsubsection{Equations}

After establishing the input parameters, the next step is to make the link between the encodings and mathematical equations.

The mathematical relations for shaft 1 and gear $\mathrm{Z1}$ are introduced into the special module of the Creo Parametric software called "Relations", and then the program validates the correctness of the information and checks if the encodings correlate with mathematical relationships (Figure 6).
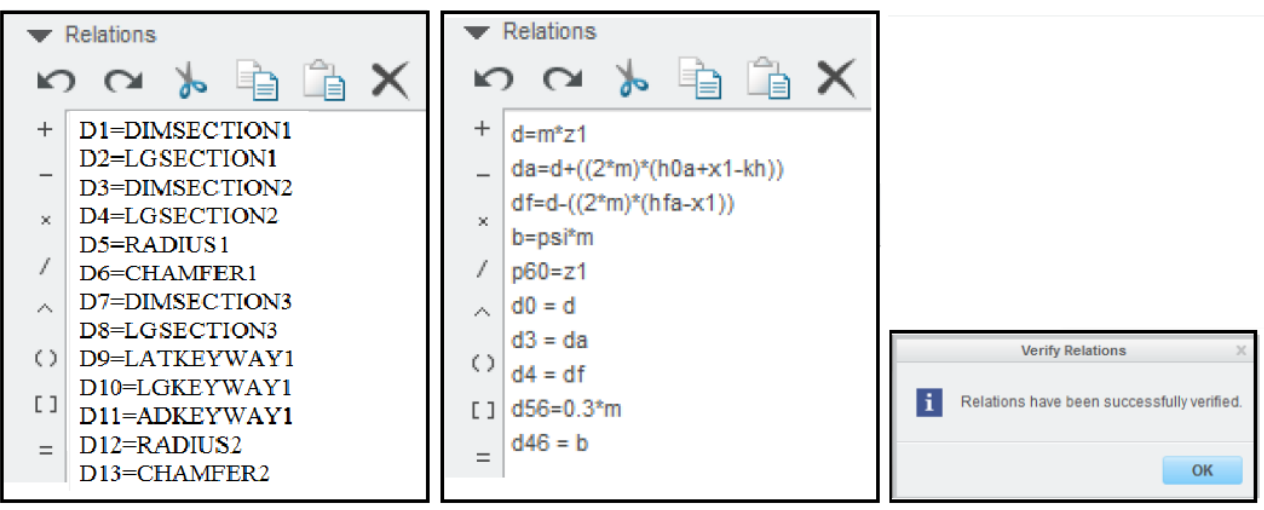

Fig. 6. Relations and validation tool for Shaft 1 and Gear Z1.

\subsubsection{Output data}

Establishing the input parameters and validating the mathematical relationships, described above, correlated with these parameters converge to the setting and realization of the output data.

In the case study, a parametric and modular product structure that can be easily optimized by modifying only the setting parameters but taking into account the imposed limit conditions results as output data, (Figure 7).
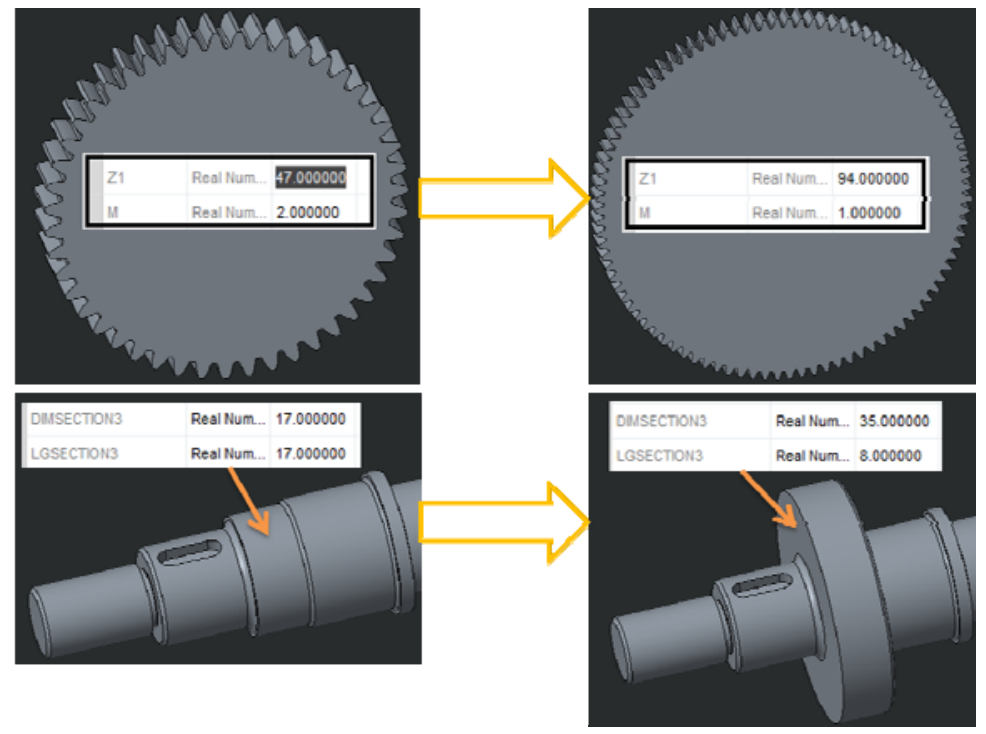

Fig. 7. Initial and modified 3D models for Shaft 1 and Gear Z1. 
In Figure 7 it can be observed that respecting the parameterized design structure INPUT-EQUATIONS-OUTPUT leads to the optimization of the design times for shaft 1 and gear Z1 (Example: Modifying the number of teeth from 47 in 94 and the module from 2 in 1 , a parameterized $3 \mathrm{D}$ model with $\mathrm{Z}=94$ and $\mathrm{m}=2$ results, respecting the limit conditions).

\section{Conclusions}

As a first conclusion, we can say that by exploiting the advanced capabilities of parametric design provided by the $\mathrm{CAD} / \mathrm{CAE}$ software solutions and using some mathematical algorithms/equations necessary to satisfy the final product development requirements, leads to enhancing the effectiveness and efficiency of Product Design activities and of Product Development Sustainability.

As another conclusion of the research approach, the theoretical elements presented in the paper are part of a large category of fundamental research concepts regarding de optimization of product structure design and of product detailed engineering design by exploiting the flexibility offered by $\mathrm{CAD} / \mathrm{CAE}$ software design tools, including by incorporation of some principles, concepts, strategies, methods.

For the future, a few research development directions on parameterized design are identified such as the approaching on some other methods (Interoperability, Model Basic Definition etc.) and principles such as DfX (DfM, DfA, DfD, DfR, etc.), Axiomatic Design Theory.

\section{References}

1. D. Manolea, Constructive Design by Pro Engineer (Publishing House of the Lucian Blaga University of Sibiu, 2010)

2. V. Govindharajan, A.N. Singh, Automated generic parameterized design of aircraft fairing and windshield (Linkoping, 2011).

3. J. Wassim, Parametric Design for Architecture, (Laurence King, 2013)

4. V. Merticaru, M.I. Ripanu, M.A. Mihalache, Applied Mechanics and Materials 371, 499-503 (2013)

5. I.M. Pista et al., Bulletin of the Polytechnic Institute of Iasi, Machine Construction 63(67) no.3, 9-20 (2017)

6. M.M. Cucos et al., Bulletin of the Polytechnic Institute of Iasi, Machine Construction 63(67) no.3, 21-40 (2017)

7. V. Merticaru, G. Nagit, B. Pralea, R. Oana, AJME 12, $43-48$ (2014)

8. V. Merticaru, M.I. Ripanu, M.A. Mihalache, M.M. Cucos, Mechanics and Materials 809-810, 1492-1497 (2015)

9. M.M. Cucos, Master Degree Thesis, (TUIASI 2016)

10. PTC, Creo Parametric (2017) 